\title{
EXPLORING THE INFLUENCES OF THE USE OF ELEMENTS COMPRISING INFORMATION SYSTEM DEVELOPMENT METHODOLOGIES ON STRATEGIC BUSINESS GOALS
}

\author{
Tomaž HOVELJA ${ }^{\mathrm{a}}$, Olegas VASILECAS ${ }^{\mathrm{b}}$, Damjan VAVPOTIČc \\ ${ }^{a, c}$ Faculty of Computer and Information Science, University of Ljubljana, \\ Večna pot 113, 1000 Ljubljana, Slovenia \\ ${ }^{b}$ Information Systems Research Laboratory, Vilnius Gediminas Technical University, \\ Sauletekio al. 11, LT-10223 Vilnius, Lithuania
}

Received 27 December 2014; accepted 30 June 2015

\begin{abstract}
As the competitive pressure of the global market for information systems (IS) continues to increase, IS development enterprises should start to consider if and how the use of IS development methodologies (ISDM) influences their main strategic business goals. More precisely, they should start to consider two different dimensions of the actual use of ISDM: the number of times an opportunity for ISDM use arises and the number of times the ISDM is actually used. Otherwise, they run the risk of mismanaging their ISDM-related investments. The goal of this study is to develop a model that would enable academics and IS practitioners to better examine and understand how different dimensions of the use of ISDM influence strategic business goals of cost leadership, differentiation and cornering niche markets in IS development enterprises. Given the limited literature on the research topic, this study was considered exploratory and theory building in nature. The main result of the presented exploratory study is a clearly defined model for examining how different dimensions of ISDM influence strategic business goals. Exploratory results show that the actual use of ISDM has a significantly positive influence on strategic business goals of differentiation and cornering of niche markets, but not the cost leadership.
\end{abstract}

Keywords: information systems development methodologies, strategic management, evaluation of information systems development methodologies, strategic business goals.

JEL Classification: C8.

\section{Introduction}

An information systems development methodology (ISDM) can be defined as a collection of elements, such as activities, procedures, techniques, tools, and documentation aids, which help information systems (IS) developers in their efforts to implement a new IS

Corresponding author Olegas Vasilecas

E-mail: olegas.vasilecas@vgtu.lt 
(Avison, Fitzgerald 2006). For SMEs in the IT industry, ISDMs are one of the key R\&D process innovations as they are crucial for building of a successful IS (White Baker 2011). Since $R \& D$ activities are crucial for product or process innovations in a firm (Lin et al. 2013), it is not surprising that ISDM have been a topic of significant interest to researchers and practitioners over the past three decades (Basole et al. 2013). The current global transformation into the creation and modernisation of a sustainable knowledge-based society and sustainable knowledge economy is a very complicated process (Melnikas 2010; Dudzeviciute et al. 2014), which, among other things, requires new information and communication systems (Sakalauskas 2010) in need of new strategic and methodological approaches (Hovelja et al. 2013).

In the past decades, various ISDM emerged that were based on different underlying philosophies and were developed in both academic and commercial environments. The main motive for their creation was to introduce formal ISDM elements (e.g. procedures, methods, techniques, tools and documentation aids) that would produce higher quality IS at an acceptable cost and reduce software project failure rates that remain alarmingly high (Vrhovec et al. 2015). However, many organisations dealing with IS development do not use such ISDM and rely mainly on ad hoc development practices. Different reasons for this situation have been identified (Khalifa, Verner 2000; Riemenschneider et al. 2002) and considerable efforts have been invested into the selection of suitable ISDM (Vavpotic, Vasilecas 2012) and improvement of the use of ISDM elements in IS development organisations (White Baker 2011; Vavpotic, Bajec 2009; Vavpotic, Hovelja 2012).

Moreover, the assumption that the use of ISDM elements is a strictly technical decision is frequently encouraged by the rest of the organisation (Avison, Fitzgerald 2006). The use of ISDM elements is typically considered as a technical issue with a focus on the goals and benefits of the developers (Karlsson 2013). Research on ISDM elements in general focuses on answering the question how ISDM elements are used without asking if they are actually used (Gorschek et at. 2014). However, use of ISDM elements typically involves a considerable investment of time, effort and money. Therefore, it is argued that business managers, in general, should participate more actively in such decision-making (Avison, Fitzgerald 2006; Hovelja et al. 2013).

In this paper, we examine if and how ISDM elements influence strategic goals of an enterprise to advance the theoretical understanding of benefits related to ISDM elements. Such theoretical advancement would align models in the field of ISDM use with models in the field of IS implementation and use. The IS implementation and use models link IS use to strategic benefits of enterprises through their collective influences on the conduct of individual users (Mirani, Lederer 1998; Delone, Mclean 2003). Similar links between the improvement of IS development process and the strategic benefits for software development enterprises were also observed (Pino et al. 2010). ISDM elements are important for IS development process. Therefore, the influence of ISDM elements on strategic business goals of an enterprise merits further investigation.

The following research questions were posed to improve significantly the vision regarding the purpose and frequency ISDM elements: How can/should we measure the influences of use of ISDM elements on enterprise strategic business goals (RQ1)? Should the use 
of ISDM elements be considered of strategic importance for IS development enterprises (RQ2)? Does the use of ISDM elements influence enterprise strategic business goals (RQ3)? To answer these questions, the relevant literature was reviewed. The findings are presented in the next section. The purpose of this exercise was to develop a model that would evaluate the link between ISDM and strategic business goals of an enterprise. Then in the following section, we address all the methodological issues that need to be solved before the model can be statistically tested. Next, we present the results of our exploratory study conducted on IS development enterprises in Slovenia. We conclude the article with a discussion of the technological and managerial implications of our results.

\section{Related works}

Rogers' diffusion of innovations theory (Rogers 2003) forms the backbone of the research on the use of ISDM in IS development enterprises (Gallivan 2003; Green et al. 2005; Huisman, Iivari 2003). Studies in the field of the use of ISDM view ISDM or its elements as innovations and try to predict and explain adopter attitudes and their innovation-related behaviour (Gallivan 2001). In addition to the Rogers' theory, other models and theories can be used to predict/explain the use of innovations in the field of IT and ISDM (Aboelmaged 2010; Venkatesh, Davis 2000; Wang et al. 2013). These theories generally neglect business aspects of the use of ISDM, which play a key role in strategic investment decisions of an enterprise even though academics (e.g. Avison, Fitzgerald 2006) and practitioners (e.g. IBM 2006) claim that ISDM is beneficial to IS development enterprises. Thus, these inconsistencies remain an open issue that needs to be addressed.

The research on the use of ISDM typically observes an ISDM as a whole or a single element of an ISDM (e.g. a development technique), but does not consider an ISDM as a system of interrelated elements. Consequentially, differences between ISDM elements are overlooked. However, the use of elements of the same ISDM can differ considerably (Vavpotic, Bajec 2009). Such view is also acknowledged by the situational method engineering (Karlsson, Agerfalk 2009; Ralyte et al. 2003) that aims to build an ISDM fit for a certain situation from elements of several existing ISDM. An ISDM is typically constructed from elements of different ISDM; therefore, it is important to study the performance of an ISDM on the level of its elements (Vavpotic, Bajec 2009).

To select the most appropriate strategic business goals and answer the paper's research questions, we reviewed the established theories of competitive advantage and enterprise (firm) (Tambovcevs 2012). Porter's competitive strategy (Porter 1998; Akcagun, Dal 2014) was a significant breakthrough for the analysis of ways to achieve strategic business goals and is widely adopted in theory, practice and teaching. Porter's three generic strategies are cost leadership, differentiation and cornering niche markets. Cost leadership is a strategic business goal that is common to many standard microeconomic models (Chandler 1984; Putterman, Kroszner 1996; Banker et al. 2014). Similarly, differentiation and cornering niche markets have been identified as important strategic business goals (Allen et al. 2012; Hagen et al. 2012). 
Porter asserted (1998) that an enterprise can only choose one of the three strategic business goals as a basis for successful competition. However, this preposition was challenged by many researchers and world-class manufacturing enterprises (Belekoukias et al. 2014; Lau 2002; Miller 1992). For this reason, we measured the non-exclusive influence of ISDM on all three strategic business goals.

\section{Proposed model}

The proposed model is based on the findings of the above presented related works. To answer the paper's research questions, we first had to consider that the use of ISDM is a multi-dimensional issue involving different stakeholders. Therefore, it is difficult to measure directly the influences of the use of ISDM on strategic business goals, unless well-established measurement systems exist in the observed organisations. Unfortunately, only a few organisations systematically measure their development process. Therefore, we decided to focus on perceptions of key employees that have a deep understanding of their enterprise's ISDM and their enterprise's strategic business goals rather than using direct measurements. A similar approach was also used in other ISDM studies (Huisman, Iivari 2006; Vavpotic, Bajec 2009).

We followed the research presented in the related work section and measured the use of ISDM on the level of ISDM elements, e.g. procedures, methods, techniques, tools and documentation aids. In this way, we aimed to gain a deeper understanding of influences related to the use of ISDM elements on strategic business goals as discussed in the introduction. We compared the same measures applicable to the use of ISDM and strategic business goal measures for all the ISDM elements to enable the analysis of different ISDM elements.

To understand how the use of ISDM influences strategic business goals, we propose a model that can be used to analyse the link between the use of ISDM and the achievement of strategic business goals. The existing studies in the field of the use of ISDM often utilise only a single measure of actual use (AU) of a specific ISDM element (e.g. Huisman, Iivari 2002). The single measure (Turner et al. 2010) can be a self-reported measure (i.e. user reported frequency and intensity of the use of the technology or its element) or an objective measure (i.e. the number of log-ons to the system). All but one of the primary studies that measured actual use, employed self-reported use rather than objective measures (Legris et al. 2003). However, a single measure cannot capture the differences in views of developers and technical managers regarding ISDM elements. To address this issue, we lean on existing general research in the field of diffusion of IT innovations (Fichman, Kemerer 1999). Fichman and Kemerer detected significant and persistent differences between the acquisition and the use (deployment) of IT innovations termed assimilation gaps. Similar gaps were also found in specific research focusing on adoption of ISDM elements (Vavpotic, Bajec 2009). In order to capture these assimilation gaps, we split AU into two dimensions, namely, potential use (PU) and relative use (RU). On the one hand, PU measures how frequently an opportunity to use a certain ISDM element arises during the IS development disregarding whether the developers actually use the ISDM element. PU is evaluated by technical managers that understand how many (number of) opportunities 
there are for application of a specific ISDM element in their IS development enterprise. On the other hand, RU measures the percentage of opportunities that a specific ISDM element was actually used by the developer. Only direct users of an ISDM element evaluate RU. The theoretical relationships between AU, PU and RU are shown in Equation 1.

$$
A U=P U \times R U .
$$

For instance, if technical managers estimate that a specific ISDM element can be often used during an IS development project (PU), and developers estimate that they use this element approximately in only $40-60 \%$ of opportunities (RU), the specific ISDM element is infrequently used (AU).

After developing adequate measures for the use of ISDM for our model, we focused on selecting the appropriate strategic business goals for an IS development enterprise. These variables will complete our model by linking the measures for the use of ISDM to strategic business goals. Based on the related works, we selected cost leadership (CL), differentiation (DF) and cornering niche markets (NM) as the three studied strategic business goals. Only technical managers evaluated the influences of ISDM on strategic business goals as only they have the technical and business knowledge and understanding needed to evaluate these influences. Figure 1 shows the entire proposed model.

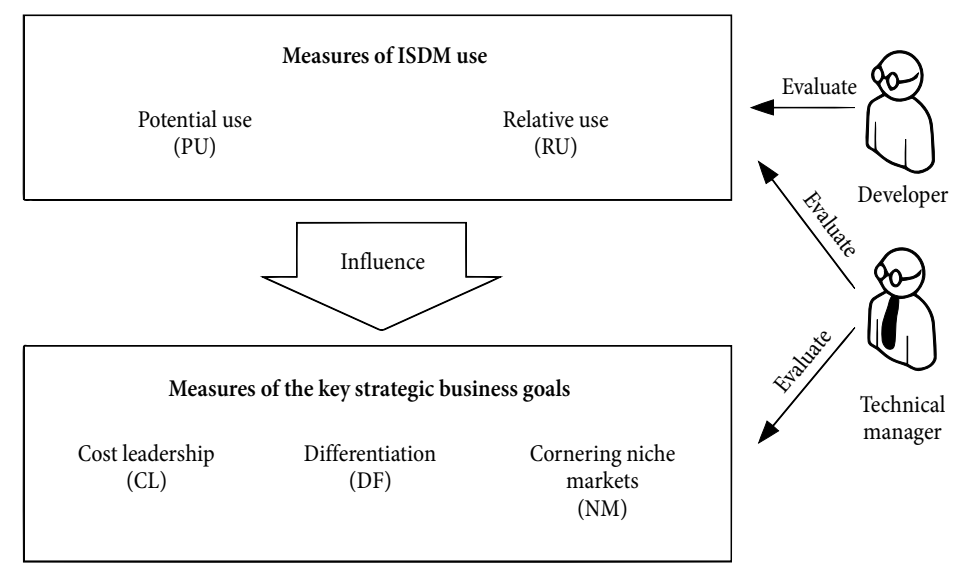

Fig. 1. The model depicting the influence of the use of ISDM on strategic business goals

\section{Method}

In our exploratory study, we included five small and medium enterprises (SMEs), considered to be typical Slovenian software development SMEs. The research took place in enterprises with similar development processes, products, culture and underlying technology. The development process in all studied enterprises was based on standard software development lifecycle phases including system analysis, system design, development, integration and testing. Each enterprise was asked to evaluate the key ISDM elements of each phase (for instance, in system analysis phase, they evaluated acquisition of requirements, the for- 
malization of requirements, review of requirements, etc.). We interviewed 38 key technical managers and key developers that were directly involved in the use of the studied ISDM elements in the studied enterprises. Technical managers were members of middle and top management that had a comprehensive overview of both technical and business aspects of studied ISDM elements. As such they are most able to evaluate objectively the technical and strategic value of these ISDM elements. The interviewees occupied similar positions and typical software development roles in different enterprises. Technical manager were asked to name and evaluate the potential use and the influence on strategic business goals of those ISDM elements that were a part of the software development phases they were responsible for. Each developer was asked to evaluate the relative use of those ISDM elements that were a part of the software development phases they participated in on a regular basis. In this manner, we ensured that interviewees did not evaluate ISDM elements, which they did not know. The survey participants were selected based on their involvement in each phase (programmers, developers, testers, etc.). The details of the participating enterprises and the number of interviewees are presented in Table 1.

Table 1. The details of the participating enterprises and the number of interviewees

\begin{tabular}{|c|c|c|}
\hline Short description of SME & $\begin{array}{l}\text { key technical } \\
\text { managers }\end{array}$ & $\begin{array}{c}\text { key } \\
\text { developers }\end{array}$ \\
\hline $\begin{array}{l}\text { SME that develops web based applications in the field of finance. } \\
\text { They focus on the development of the management IS. }\end{array}$ & 2 & 4 \\
\hline $\begin{array}{l}\text { SME that builds and supports its own ERP solution that can be } \\
\text { tailored to the needs of specific clients. Their clients are mainly from } \\
\text { batch production industries. }\end{array}$ & 3 & 6 \\
\hline $\begin{array}{l}\text { SME that produces its own pre-packaged ERP solution for small } \\
\text { businesses. The solution consists of several standardized components } \\
\text { that can be purchased separately. }\end{array}$ & 3 & 5 \\
\hline $\begin{array}{l}\text { SME developing specialised business solutions for corporate } \\
\text { and commercial banking. Most of their solutions are focused on } \\
\text { improving the loan application process. }\end{array}$ & 2 & 5 \\
\hline $\begin{array}{l}\text { SME focusing on development of web based business applications } \\
\text { mainly in the CRM field. Their product portfolio includes } \\
\text { applications for web shops, customer web support and CRM analytics. }\end{array}$ & 4 & 4 \\
\hline
\end{tabular}

The questionnaire included five questions for each evaluated ISDM element: two questions for the evaluation of the two dimensions of a specific use of ISDM element (PU and $\mathrm{RU}$ ) and three questions for the evaluation of the influence of a specific ISDM element on one of the three strategic business goals (CL, DF and NM). The 5 questions concerning each evaluated ISDM element and their measurement scales are presented in Table 2 . The measurement scales were coded from 1 to 7 in all cases except for the variable RU, where the measurement scale was coded as the adequate percentage for each scale level. Altogether, we evaluated 67 ISDM elements that the interviewed technical managers identified as the ones that are being used in their enterprises. 
Table 2. The five questions used for the evaluation of each ISDM element

\begin{tabular}{lll}
\hline \multicolumn{1}{c}{$\begin{array}{c}\text { Studied } \\
\text { variables: }\end{array}$} & $\begin{array}{l}\text { Questions posed to interviewees } \\
\text { for each studied ISDM element: }\end{array}$ & \multicolumn{1}{c}{ Used measurement scales: } \\
\hline $\begin{array}{l}\text { Potential } \\
\text { use } \\
\text { (PU) }\end{array}$ & $\begin{array}{l}\text { How often does an opportunity } \\
\text { arise to use [the ISDM element } \\
\text { name] regardless of its actual use. }\end{array}$ & $\begin{array}{l}\text { Never, very rarely, rarely, sometimes, often, } \\
\text { almost always, always. }\end{array}$ \\
\hline $\begin{array}{l}\text { Relative } \\
\text { use } \\
\text { (RU) }\end{array}$ & $\begin{array}{l}\text { Given the opportunity to use [the } \\
\text { ISDM element name], how often } \\
\text { do you use it? }\end{array}$ & $\begin{array}{l}\text { Never, in up to 20\% of opportunities, from } \\
20 \% \text { up to 40\% of opportunities, from } 40 \% \\
\text { up to 60\% of opportunities, from 60\% up to } \\
80 \% \text { of opportunities, in more than } 80 \% \text { of } \\
\text { opportunities but not always, always. }\end{array}$ \\
\hline $\begin{array}{l}\text { Cost } \\
\text { leadership } \\
\text { (CL) }\end{array}$ & $\begin{array}{l}\text { [the ISDM element name] helps to } \\
\text { decrease the development costs } \\
\text { of a product or service. }\end{array}$ & $\begin{array}{l}\text { Strongly disagree, disagree, somewhat disagree, } \\
\text { neither agree nor disagree, somewhat agree, } \\
\text { agree, strongly agree. }\end{array}$ \\
\hline $\begin{array}{l}\text { Different- } \\
\text { iation (DF) }\end{array}$ & $\begin{array}{l}\text { [the ISDM element name] helps us } \\
\text { to develop a better product }\end{array}$ & $\begin{array}{l}\text { Strongly disagree, disagree, somewhat disagree, } \\
\text { neither agree nor disagree, somewhat agree, } \\
\text { agree, strongly agree. }\end{array}$ \\
\hline $\begin{array}{l}\text { Niche service. } \\
\text { markets } \\
\text { (NM) }\end{array}$ & $\begin{array}{l}\text { [the ISDM element name] helps } \\
\text { the organisation in the achievement } \\
\text { of its goals by focusing on one or a } \\
\text { few segments. }\end{array}$ & $\begin{array}{l}\text { Strongly disagree, disagree, somewhat disagree, } \\
\text { neither agree nor disagree, somewhat agree, } \\
\text { agree, strongly agree. }\end{array}$ \\
\hline & & \\
\hline
\end{tabular}

\section{Results}

The descriptive statistics of the studied variables are presented in Table 3 . The mean and standard error of the mean for PU and AU show that there is a significant difference between the two measures related to the use of ISDM, which supports the premise of this study that the use of ISDM should be understood as a multi-dimensional construct. The results also show that skewness and kurtosis did not exceed the ranges that would violate the assumptions regarding the normal distribution of the variables (Barrett et al. 2005; Ozgur, Strasser 2004; Anderson et al. 2009).

To improve the understanding of these results, we proceeded with Pearson correlation analysis between the different measures related to the use of ISDM (AU, PU and RU) and the three strategic business goals (CL, DF and NM). These relationships are shown in Table 4. The correlations between AU and the three strategic goals show that the actual use

Table 3. Descriptive statistics of the studied variables

\begin{tabular}{cccccccc}
\hline & Mean & $\begin{array}{c}\text { Std. Error } \\
\text { of Mean }\end{array}$ & Median & $\begin{array}{c}\text { Std. } \\
\text { Deviation }\end{array}$ & Variance & Skewness & Kurtosis \\
\hline $\mathrm{AU}$ & 3.1418 & 0.19332 & 3.1500 & 1.58239 & 2.504 & 0.247 & -0.592 \\
\hline $\mathrm{PU}$ & 5.0044 & 0.13914 & 5.0000 & 1.13894 & 1.297 & -0.462 & -0.281 \\
\hline $\mathrm{RU}$ & 0.5995 & 0.02769 & 0.6250 & 0.22663 & 0.051 & -0.096 & -0.681 \\
\hline $\mathrm{CL}$ & 5.0329 & 0.13189 & 5.2500 & 1.07953 & 1.165 & -0.380 & -0.958 \\
\hline $\mathrm{DF}$ & 5.3864 & 0.12183 & 5.6000 & 0.99722 & 0.994 & -0.569 & -0.377 \\
\hline $\mathrm{NM}$ & 5.3558 & 0.10123 & 5.5000 & 0.82857 & 0.687 & -0.849 & 1.051 \\
\hline
\end{tabular}


of ISDM positively influences the strategic goals of differentiation (DF) and niche markets (NM), but not cost leadership (CL). For PU, all three correlations with strategic business goals are positive and significant while RU is correlated positively and significantly only to the strategic business goal of differentiation. This indicates that technical managers perceive the potential use of ISDM as positively connected to all three strategic business goals. However, the developers often do not seem to use those ISDM elements that importantly influence cost leadership (CL) and niche markets (NM) as often as those ISDM elements that importantly influence differentiation (DF). This lowers the influence of the actual use of ISDM elements on the two strategic goals, especially cost leadership and partially on niche markets.

Table 4. Pearson correlations of the use of ISDM and Enterprise Productivity Measures

\begin{tabular}{ccccccc}
\hline \multicolumn{1}{c}{$\mathrm{AU}$} & $\mathrm{PU}$ & $\mathrm{RU}$ & $\mathrm{CL}$ & $\mathrm{DF}$ & $\mathrm{NM}$ \\
\hline $\mathrm{AU}$ & 1 & & & & & \\
\hline $\mathrm{PU}$ & $0.782^{\star \star}$ & 1 & & & & \\
\hline $\mathrm{RU}$ & $0.935^{\star *}$ & $0.558^{\star *}$ & 1 & & & \\
\hline $\mathrm{CL}$ & 0.223 & $0.259^{\star}$ & 0.208 & 1 & & \\
\hline $\mathrm{DF}$ & $0.338^{\star *}$ & $0.331^{\star \star}$ & $0.370^{\star *}$ & $0.297^{\star}$ & 1 & 1 \\
\hline $\mathrm{NM}$ & $0.320^{\star *}$ & $0.414^{\star *}$ & 0.191 & $0.321^{\star *}$ & 0.172 & \\
\hline
\end{tabular}

Note: ${ }^{\star} \mathrm{p}<0.05 ;{ }^{\star *} \mathrm{p}<0.01$.

For instance, the ISDM element - Data Model Updating is an activity performed regularly to assure consistency of data model and actual database schema. Although it is partially automated, it typically requires manual interventions and is regularly chosen by developers. Technical managers perceive it to have a positive influence on DF as this SME attempts to distinguish itself from its competitors by achieving higher quality of products and in their opinion the quality of the data model is a key contributor to the quality of their product. However, they also perceive it to have a neutral influence on cost leadership because it is only partially automated. Additionally, technical managers perceive that this ISDM element influences NM negatively since this ISDM element prescribes that changes to the database are made only on a monthly basis, thus limiting the creativity of the developers to tailor the product to specific niche markets.

The correlations between DF and AU, PU, RU are positive and statistically significant. Therefore, we can conclude that use of ISDM elements positively influences the enterprises strategic capability to differentiate its products from the competition.

We performed Student's independent sample t-test analysis (Sharma 1996) to additionally demonstrate the importance of differentiating between the different measures of ISDM use. To avoid any multivariate issues concerning the robustness of the statistical analysis we merged the two ISDM use scales namely PU and RU into one ordinal scale consisting of four groups in accordance with the four groups that form the ISDM evaluation model (Vavpotic, Bajec 2009). The four groups represent the four quadrants of a scatter-plot of all ISDM elements separated by the medians of PU and RU of the studied ISDM ele- 
ments. Two of these groups had 11 and 8 ISDM elements each and were thus too small for Student's independent sample t-test analysis, the other two groups consisted of 25 and 23 ISDM elements and were of the appropriate size for Student's independent sample t-test analysis (Sharma 1996).

One of these groups is the group of ISDM elements with high AU and consists of ISDM elements that are above both PU and RU median of all the studied ISDM elements. The other group is the group of ISDM elements with low AU and consists of ISDM elements that are below both PU and RU median of all the studied ISDM elements. Our statistical analysis focuses on the differences between these two large groups since they are of major interest for our research as discussed in the previous paragraph.

Table 5. Student's independent t-tests of enterprise performance measures between "High AU" and "Low AU" groups of ISDM elements

\begin{tabular}{clcccc}
\hline & & $\mathrm{F}$ & Sig. & $\mathrm{T}$ & Sig. (2-tailed) \\
\hline $\mathrm{CL}$ & Equal variances not assumed & 7.816 & 0.008 & -1.572 & 0.123 \\
\hline $\mathrm{DF}$ & Equal variances not assumed & 8.467 & 0.006 & -2.160 & 0.037 \\
\hline $\mathrm{NM}$ & Equal variances assumed & 0.446 & 0.508 & -3.078 & 0.004 \\
\hline
\end{tabular}

The results of the analysis are shown in Table 5. Two of the three strategic business goals measures differ significantly between the two studied groups of the use of ISDM elements. Specifically, the influence of the use of ISDM elements on the strategic business goals of differentiation (DF) and cornering niche markets (NM) is significantly higher in high AU group. However, the strategic business goal of cost leadership (CL) does not exhibit significant differences between the high and the low AU groups.

\section{Discussion}

Based on all of the above-presented results, we can conclude that our exploratory results show that some dimensions regarding the use of ISDM influence specific strategic business goals, while others do not. Such results show that the influence of the use of ISDM on the key strategic business goals merits further investigation, in which the use of ISDM should be viewed as a multi-dimensional construct. The fact that strategic business goals (CL, $\mathrm{NM}$ ) correlate with measures related to the use of ISDM that evaluates the perceptions of technical managers (PU), but do not correlate with the measure of ISDM use that evaluates the perceptions of developers (RU) likely represents a conflict of interests between the two dominant internal interest groups in the IS development enterprises. Technical managers and developers both play a key role in deciding if and how often ISDM elements will be used in an enterprise; however, the results indicate they often have different, even conflicting views about the benefits of use of specific ISDM elements.

As expected, all three strategic business goals are positively affected by the potential use (PU); while only the strategic business goal of differentiation is positively affected by the relative use (RU) of the ISDM elements (RQ3). Thus, we can state that technical managers 
consider the use of ISDM elements of strategic importance, regardless of which strategic business goals they influence (RQ2).

The analysis exposed the fact that the difference in interests between technical managers and developers significantly influences the effect of the use of ISDM elements on two strategic business goals (CL and NM). In our opinion, this is the underlying cause of perceptual incongruence of ISDM between IS developers and managers discussed by $\mathrm{Hu}$ issman and Iivari (Huisman, Iivari 2006). Such perceptual incongruence, if left untreated, causes un-called for ISDM improvisations and ISDM outcomes conflicting with strategic business goals (Tjornehoj, Mathiassen 2010). Thus, management should pay special attention and regularly evaluate the alignment of interests between these two groups. From this perspective, the proposed model can be used as a tool that enables managers to conduct such regular evaluations (RQ1).

We can further claim that only through the measurement of multiple relevant dimensions of performance one can better understand the link between the use of ISDM elements and strategic business goals. Such findings are in line with present-day expectations of multiple stakeholder involvement, diverse motivations and conflicting goals present in IS development (Soh et al. 2010).

\section{Conclusions and future work}

In this paper, we addressed the question if and how we should measure the influences of the use of ISDM elements on the key strategic business goals. The proposed model comprises multiple dimensions of the use of ISDM (PU and RU) and the key strategic business goals of IS development enterprises (CL, DF and NM). The empirical tests of the proposed model show that there are several positive and statistically significant influences of the use of ISDM elements on key strategic business goals (RQ3). Therefore, the use of ISDM elements should be considered of strategic importance (RQ2). The results also confirmed that our model could be successfully used to measure the influences of the use of ISDM elements on strategic business goals (RQ1).

The study findings are subjected to the following limitations. The proposed model was tested through exploratory research that included five representative IS development SMEs. Thus, before one can generalize the research findings, further investigation is needed that would include enterprises from different countries and broaden their size, type, number and profiles of products.

Further research should focus on the question whether the key strategic business goals sufficiently describe the interests of the key interest groups and if in addition to technical managers and developers other interest groups should be introduced in the model. Furthermore, we see a possibility to expand the set of measures of ISDM use by considering how sophisticated the use of the ISDM elements is. Such measurement could introduce the quality of use as an important additional factor that moderates the interaction between the use of ISDM and strategic business goals. 


\section{References}

Aboelmaged, M. G. 2010. Predicting e-procurement adoption in a developing country, Industrial Management \& Data Systems 110(3): 392-414. http://dx.doi.org/10.1108/02635571011030042

Akcagun, E.; Dal, V. 2014. The use of M. Porter's generic strategies in the Turkish apparel industry and strategy proposals for companies, Tekstil ve konfeksiyon 24(2): 151-157.

Allen, R.; Parrish, E.; Cassill, N. L.; Oxenham, W. 2012. Assessing the validity of a niche strategy model in predicting the potential and success of niche markets and products, Journal of the Textile Institute 103(8): 900-911. http://dx.doi.org/10.1080/00405000.2011.627156

Anderson, R. E.; Black, W. C.; Hair, J. F.; Babin, B. J. 2009. Multivariate data analysis. 5th ed. London: Prentice Hall International. 816 p.

Avison, D. E.; Fitzgerald, G. 2006. Information systems development: methodologies, techniques and tools. 4th ed. McGraw-Hill.

Banker, R.; Mashruwala, R.; Tripathy, A. 2014. Does a differentiation strategy lead to more sustainable financial performance than a cost leadership strategy?, Management Decision 52(5): 872-896. http://dx.doi.org/10.1108/MD-05-2013-0282

Barrett, K. C.; Leech, N. L.; Morgan, G. A. 2005. SPSS for intermediate statistics: use and interpretation. 2nd ed. London: Lawrence Erlbaum Associates.

Basole, R. C.; Seuss, C. D.; Rouse, W. B. 2013. IT innovation adoption by enterprises: knowledge discovery through text analytics, Decision Support Systems 54(2): 1044-1054. http://dx.doi.org/10.1016/j.dss.2012.10.029

Belekoukias, I.; Garza-Reyes, J.; Kumar, V. 2014. The impact of lean methods and tools on the operational performance of manufacturing organisations, International Journal of Production Research 52(18): 5346-5366. http://dx.doi.org/10.1080/00207543.2014.903348

Chandler, A. D. 1984. The emergence of managerial capitalism, The Business History Review 58(4): 473-503. http://dx.doi.org/10.2307/3114162

Delone, W.; Mclean, E. 2003. The DeLone and McLean model of information systems success: a tenyear update, Journal of Management Information Systems 19(4): 9-30.

Dudzeviciute, G.; Maciulis, M.; Tvaronaviciene, M. 2014. Structural changes of economies: Lithuania in the global context, Technological and Economic Development of Economy 20(2): 353-370. http://dx.doi.org/10.3846/20294913.2014.915597

Gallivan, M. J. 2001. Organizational adoption and assimilation of complex technological innovations: development and application of a new framework, ACM SIGMIS Database - Special issue on Adoption, Diffusion, and Infusion of IT 32(3): 51-85.

Gallivan, M. J. 2003. The influence of software developers' creative style on their attitudes to and assimilation of a software process innovation, Information \& Management 40(5): 443-465. http://dx.doi.org/10.1016/S0378-7206(02)00039-3

Gorschek, T.; Tempero, E.; Angelis, L. 2014. On the use of software design models in software development practice: an empirical investigation, Journal of Systems and Software 95: 176-193. http://dx.doi.org/10.1016/j.jss.2014.03.082

Green, G. C.; Hevner, A. R.; Collins, R. W. 2005. The impacts of quality and productivity perceptions on the use of software process improvement innovations, Information and Software Technology 47(8): 543-553. http://dx.doi.org/10.1016/j.infsof.2004.10.004

Fichman, R.; Kemerer, C. 1999. The illusory diffusion of innovation: an examination of assimilation gaps, Information Systems Research 10(3): 255-275. http://dx.doi.org/10.1287/isre.10.3.255 
Hagen, B.; Zucchella, A.; Cerchiello, P.; De Giovanni, N. 2012. International strategy and performanceclustering strategic types of SMSs, International Business Review 21(3): 369-382. http://dx.doi.org/10.1016/j.ibusrev.2011.04.002

Hovelja, T.; Vasilecas, O.; Rupnik, R. 2013. A model of influences of environmental stakeholders on strategic information systems planning success in an enterprise, Technological and Economic Development of Economy 19(3): 465-488. http://dx.doi.org/10.3846/20294913.2013.818591

Huisman, M.; Iivari, J. 2002. The individual deployment of systems development methodologies: lecture notes in computer sciences, vol. 2348. Springer Link, 134-150.

http://dx.doi.org/10.1007/3-540-47961-9_12

Huisman, M.; Iivari, J. 2003. The organisational deployment of systems development methodologies, in Kirikova et al. (Eds.). Information systems development: advances in methodologies, components, and management. Kluwer Academic/Plenum Publishers, 87-100.

Huisman, M.; Iivari, J. 2006. Deployment of systems development methodologies: perceptual congruence between is managers and systems developers, Information \& Management 43(1): 29-49. http://dx.doi.org/10.1016/j.im.2005.01.005

IBM. 2006. Rational unified process v 7.0.1 IBM rational method composer plugin, Version 7.0.1: IBM Corp.

Karlsson, F. 2013. Longitudinal use of method rationale in method configuration: an exploratory study, European Journal of Information Systems 22(6): 690-710. http://dx.doi.org/10.1057/ejis.2012.30

Karlsson, F.; Agerfalk, P. 2009. Exploring agile values in method configuration, European Journal of Information Systems 18(4): 300-316. http://dx.doi.org/10.1057/ejis.2009.20

Khalifa, M.; Verner, J. M. 2000. Drivers for software development method usage, IEEE Transactions on Engineering Management 47(3): 360-369. http://dx.doi.org/10.1109/17.865904

Lau, R. S. M. 2002. Competitive factors and their relative importance in the US electronics and computer industries, International Journal of Operations \& Production Management 22(1): 125-135. http://dx.doi.org/10.1108/01443570210412105

Legris, P.; Ingham, J.; Collerette, P. 2003. Why do people use information technology? A critical review of the technology acceptance model, Information and Management 40(3): 191-204. http://dx.doi.org/10.1016/S0378-7206(01)00143-4

Lin, E. S.; Hsiao, Y.; Lin, H. 2013. Complementarities of R\&D strategies on innovation performance: evidence from Taiwanese manufacturing firms, Technological and Economic Development of Economy 19(Supplement 1): S134-S156. http://dx.doi.org/10.3846/20294913.2013.876684

Melnikas, B. 2010. Sustainable development and creation of the knowledge economy: the new theoretical approach, Technological and Economic Development of Economy 16(3): 516-540.

http://dx.doi.org/10.3846/tede.2010.32

Miller, D. 1992. The generic strategy trap, Journal of Business Strategy 13(1): 37-41. http://dx.doi.org/10.1108/eb039467

Mirani, R.; Lederer, A. 1998. An instrument for assessing the organizational benefits of IS projects, Decision Sciences 29(4): 803-838. http://dx.doi.org/10.1111/j.1540-5915.1998.tb00878.x

Ozgur, C.; Strasser, S. E. 2004. A study of the statistical inference criteria: can we agree on when to use $\mathrm{Z}$ versus t?, Decision Sciences, Journal of Innovative Education 2(2): 177-192. http://dx.doi.org/10.1111/j.1540-4609.2004.00043.x

Pino, F.; Pardo, C.; García, F.; Piattini, M. 2010. Assessment methodology for software process improvement in small organizations, Information and Software Technology 52(10): 1044-1061. http://dx.doi.org/10.1016/j.infsof.2010.04.004

Porter, M. E. 1998. Competitive strategy: techniques for analyzing industries and competitors. With a new introduction. New York: Free Press. 
Putterman, L.; Kroszner, R. S. 1996. The economic nature of the firm. Cambridge: Cambridge University Press.

Ralyte, J.; Deneckere, R.; Rolland, C. 2003. Towards a generic model for situational method engineering, in Proceedings of the 15th International Conference on Advanced Information Systems Engineering, 16-20 June 2003, Klagenfurt, Velden, Austria. Springer Berlin Heidelberg, 95-110. http://dx.doi.org/10.1007/3-540-45017-3_9

Riemenschneider, C. K.; Hardgrave, B. C.; Davis, F. D. 2002. Explaining software developer acceptance of methodologies: a comparison of five theoretical models, IEEE Transactions on Software Engineering 28(12): 1135-1145. http://dx.doi.org/10.1109/TSE.2002.1158287

Rogers, E. M. 2003. Diffusion of innovations. 5th ed. New York: Free Press.

Sharma, S. 1996. Applied multivariate techniques. New York: John Wiley and Sons.

Soh, C.; Chua, C. E. H.; Singh, H. 2010. Managing diverse stakeholders in enterprise systems projects: a control portfolio approach, Journal of Information Technology 26(1): 16-31. http://dx.doi.org/10.1057/jit.2010.13

Sakalauskas, L. 2010. Sustainability models and indicators, Technological and Economic Development of Economy 16(4): 567-577. http://dx.doi.org/10.3846/tede.2010.35

Tambovcevs, A. 2012. ERP system implementation in Latvian manufacturing and construction company, Technological and Economic Development of Economy 18(1): 67-83. http://dx.doi.org/10.3846/20294913.2012.661176

Tjornehoj, G.; Mathiassen, L. 2010. Improvisation during process-technology adoption: a longitudinal study of a software firm, Journal of Information Technology 25(1): 20-34. http://dx.doi.org/10.1057/jit.2009.20

Turner, M.; Kitchenham, B.; Brereton, P.; Charters, S.; Budgen, D. 2010. Does the technology acceptance model predict actual use? A systematic literature review, Information and Software Technology 52(5): 463-479. http://dx.doi.org/10.1016/j.infsof.2009.11.005

Vavpotic, D.; Bajec, M. 2009. An approach for concurrent evaluation of technical and social aspects of software development methodologies, Information and Software Technology 51(2): 528-545. http://dx.doi.org/10.1016/j.infsof.2008.06.001

Vavpotic, D.; Hovelja, T. 2012. Improving the evaluation of software development methodology adoption and its impact on enterprise performance, ComSIS 9(1): 165-187. http://dx.doi.org/10.2298/CSIS110503072V

Vavpotic, D.; Vasilecas, O. 2012. Selecting a methodology for business information systems development: decision model and tool support, ComSIS 9(1): 135-164. http://dx.doi.org/10.2298/CSIS110315046V

Vrhovec, S.; Hovelja, T.; Vavpotič, D.; Krisper, M. 2015. Diagnosing organizational risks in software projects: Stakeholder resistance, International Journal of Project Management 33(6): 1262-1373. http://dx.doi.org/10.1016/j.ijproman.2015.03.007

Venkatesh, V.; Davis, F. D. 2000. A theoretical extension of the technology acceptance model: Four longitudinal field studies, Management Science 46(2): 186-204. http://dx.doi.org/10.1287/mnsc.46.2.186.11926

Wang, W.; Li, X. X.; Hsieh, J.J.P.A. 2013. The contingent effect of personal IT innovativeness and IT self-efficacy on innovative use of complex IT, Behaviour \& Information Technology 32(11): 11051124. http://dx.doi.org/10.1080/0144929X.2011.566940

White Baker, E. 2011. Why situational method engineering is useful to information systems development, Information Systems Journal 21(2): 155-174. http://dx.doi.org/10.1111/j.1365-2575.2010.00352.x 
Tomaž HOVELJA. Assoc. Prof. Dr Tomaž Hovelja received his bachelor's degree, master's degree and his PhD in Business Administration from the Economic Faculty at the University of Ljubljana. He is employed as a docent at the Faculty of Computer and Information Science at the University of Ljubljana. His research areas are social, economic and organisational factors of IT deployment in enterprises and IT projects success criteria. His research has appeared in journals such as Journal of Systems and Software, Computer Science and Information Systems, Economic and Business Review for Central, South-Eastern Europe.

Olegas VASILECAS. Prof. Dr (hp). Olegas Vasilecas is full-time professor at the Information Systems Department, and principal researcher and head of Information Systems Research Laboratory of Vilnius Gediminas Technical University. He is author and co-author of more than 365 research papers and 5 books in the field of information systems development. His research interests include knowledge, represented by business rule and ontology, information systems development. He delivered lectures in 7 European universities including London, Barcelona, Athens and Ljubljana. Vasilecas carried out an apprenticeship in Germany, Holland, China, and last time in Latvia and Slovenia universities. He supervised 11 successfully defended doctoral theses and now is supervising 4 doctoral students. He was the leader of a number of international and local projects. Last time he leaded "Business Rules Solutions for Information Systems Development (VeTIS)" project carried out under High Technology Development Program of Lithuania.

Damjan VAVPOTIČ. Assoc. Prof. Dr Damjan Vavpotič works at the Faculty of Computer and Information Science of the University of Ljubljana and a member of the Information Systems Laboratory at the same university. His research interests include information systems development methodologies, IS methodology evaluation and adoption, and evaluation of e-learning and IT in pedagogical processes. His research has appeared in journals such as Information and Software Technology, Nurse Education Today, Informatica, Computer Science and Information Systems, Electronics and Electrical Engineering, and in proceedings of many international conferences. 